\title{
Using eye muscles to recover visual function, memory skills and the ability to visualize, a review of superior rectus
}

\author{
Kimberly Burnham* \\ Akamai University, Department of Complementary \& Alternative Medicine, Hilo, Hawaii, USA
}

\begin{abstract}
From the field of Neurolinguistic programming (NLP) comes the idea that when a person is speaking and looks up to the left, they are remembering images (things they have seen before). Look up to the right and they are constructing images or visual fantasies (sometimes considered lying). The superior rectus muscle of the eye enables us to look up. It is innervated by the oculomotor nerve or cranial nerve three. Here we look at conditions that affect the superior rectus muscle of the eye and exercises or techniques to strengthen it. The thesis of this article is that exercises that strengthen the muscles of the eye that enable us to look up and to the right will also have a positive effect on the ability to remember images or in other words will improve visual memory. Exercises that strengthen our ability to look up to the left will also strengthen the ability to visualize or imagine things we have never seen. Improving the health of superior rectus increases the possibility of more creativity and innovation. According to neurolingistic programming the conditions that damage the superior rectus muscle of the eye may also decrease the ability to recall visual images or imagine something a person has never seen.
\end{abstract}

\section{Introduction}

The superior rectus muscle elevates the eye, allowing the eye to look up. It is innervated by the third cranial nerve-oculomotor. Difficulty looking up due to a problem with superior rectus may occur due to trauma, orbital conjunctival cyst, a tumor or mass, lipoma, lymphoma, congenital anomalies, Graves' disease, oculomotor nerve damage, glaucoma, botulinum poisoning and more. Damage to the superior rectus muscle contributes the several vision conditions including weakness of elevation, vertical diplopia (double vision), eye pain, proptosis (abnormal protrusion of the eye), and strabismus (eye turning). Visual acuity may or may not be affected by a problem with the superior rectus muscle.

Extraoccular muscles are not ordinary skeletal muscles. Researchers report a wide variety of muscle fibers within the muscles that move the eye.

"Extraocular muscles (EOMs) are unique as they show greater variation in anatomical and physiological properties than any other skeletal muscles. The superior rectus muscle is organized into two layers: a central global layer of mainly large-diameter fibers and an outer C-shaped orbital layer of principally small-diameter fibers. Six morphologically distinct fiber types were identified within the superior rectus muscle. Four muscle fiber types, three single innervated fibers and one multiple innervated fiber, were recognized in the global layer. The single innervated fibers included red, white and intermediate fibers. They differed from one another with respect to diameter, mitochondrial size and distribution, sarcoplasmic reticulum and myofibrillar size. The orbital layer contained two distinct multiple innervated fibers in addition to the red and intermediate single innervated fibers. The orbital multiple innervated fibers were categorized into low oxidative and high oxidative types according to their mitochondrial content and distribution. The highly specialized function of the superior rectus extraocular muscle is reflected in the multiplicity of its fiber types, which exhibit unique structural features" [1]
The diversity of muscle fiber types lends itself to a greater degree of compensation in the face of variations in the environment, trauma, anatomical anomalies and degeneration. If there were only one fiber type and genetics or something in the environment damaged the eye muscles, recovery would be more difficult. In the extraocular muscles if something goes wrong, it is possible that another type of fiber will take over the missing function resulting in a greater degree of healing or compensation.

Here are some of the ways the superior rectus muscle is impacted by genetics, trauma and the environment.

\section{Trauma}

Trauma happens in many ways. One journal reported damage to the superior rectus muscle following a dog bite injury. The bite resulted in "a marked weakness of elevation and vertical diplopia [double vision], which did not settle during a period of observation lasting approximately nine months following the attack. An orthoptist examination confirmed a marked restriction of upgaze" [2].

\section{Orbital cysts and masses}

In one case of an orbital cyst, symptoms included pain and vertical diplopia. There may not be visual decline. In this 2017 case "an intermuscular cyst located in the superior rectus-levator complex is most likely of congenital embryonic conjunctival origin" [3].

Another study found progressive diplopia and proptosis [abnormal

Correspondence to: Kimberly Burnham, $\mathrm{PhD}, 3608$ South Fancher Road, Spokane, Washington, 99223, USA, Tel: (860) 221-8510; E-mail: NerveWhisperer@gmail.com

Key words: superior rectus, neurolinguistic programming, memory, remembered imagery, visualization, creativity, Innovation, trauma, eyes, vision

Received: May 21, 2017; Accepted: June 06, 2017; Published: June 08, 2017 
protrusion of the eye] with a lipoma of the superior rectus muscle. "Although extraocular muscle lipomas are very rare, with only two cases reported, they must be considered in the differential diagnosis of an orbital mass" [4].

In another study, the cause of proptosis of the eye and double vision was found to be an abnormality of the superior rectus muscle. "Visual acuity was noted as 20/20 in both eyes. Eye movement showed limited supraduction. Magnetic resonance imaging revealed an indistinct mass [B-cell lymphoma] in the orbit involving the superior rectus muscle. Supraduction limitation is due to muscular contraction disorder of the superior rectus muscle, caused by direct lymphoma cell invasion" [5].

A third study reporting on a rare case of left-sided ptosis [drooping eyelid] and restricted elevation of the left eye in an 8-year-old girl said, "A CT scan orbit and brain revealed a ring-enhancing lesion in the levator palpebral superioris and superior rectus muscle complex of the left eye and left parietal and right temporal region. The levator palpebral superioris and superior rectus muscle complex is the least common site of involvement among extraocular muscles in ocular cysticercosis" [6].

\section{Strabismus}

Another report found a correlation between strabismus, Graves' eye disease, intorsion of the eye with superior rectus and superior oblique muscle enlargement. "Preoperative superior rectus and / or superior oblique muscle enlargement appear to be a primary contributing factor relating to preoperative and postoperative intorsion in patients with Graves' eye disease-associated strabismus." [7]

In a study of 24 patients with superior oblique palsy and strabismus researchers found mechanical problems of the both the superior and inferior rectus muscles to contribute to the strabismus. "Rectus pulleys typically were displaced in superior oblique palsy. In unilateral superior oblique palsy, on average the medial rectus pulley was displaced $1.1 \mathrm{~mm}$ superiorly, the superior rectus pulley was displaced $0.8 \mathrm{~mm}$ temporally, and the inferior rectus pulley was displaced $0.6 \mathrm{~mm}$ superiorly and $0.9 \mathrm{~mm}$ nasally from normal. Displacements were similar in bilateral superior oblique palsy. Rectus pulley displacements alone, without abnormal oblique muscle contractility, can create the clinical patterns of incomitant strabismus in superior oblique palsy" [8].

There can also be structural and congenital issues with the superior rectus muscle that contributes to strabismus. "The lateral rectussuperior rectus band is an orbital connective tissue structure that has been implicated in a form of strabismus termed sagging eye syndrome. The lateral rectus-superior rectus band is visible in most patients without strabismus on coronal T1WI [CT scan]. The age effect with respect to its visibility and superotemporal bowing could represent age-related connective tissue degeneration" [9].

Sometimes the cause of the superior oblique palsy is a lax ligament (connective tissue). Researchers reported, "In unilateral congenital superior oblique palsy, a large hypertropia is sometimes associated with ipsilateral contracture of the superior rectus muscle and apparent overaction of the contralateral superior oblique. Intraoperatively, all three patients were found to have a lax ipsilateral superior oblique tendon" [10].

These journal articles raise the question of whether manual therapy techniques that address the connective tissue like myofascial release, strain and counterstrain for muscle and connective tissue or nutritional therapies addressing the connective tissue [11] could be helpful in improving upward movement and coordination of the eyes. The connective tissue of the body is also a network via which communication can take place. Tensions in the connective tissue of the eyes can affect the health of the connective tissue elsewhere in the body and vis versa [12].

\section{Botulinum and keratopathy}

Toxicity can also affect the health of the extraocular muscles. All the participants in one study had acute exposure keratopathy and they all required chemodenervation of the levator muscle to induce a protective ptosis [drooping eyelid]. "Botulinum toxin A injection to the levator palpebrae superioris muscle to induce a protective ptosis can adversely cause reduced upgaze due to diffusion of botulinum to the superior rectus muscle. Reduced upgaze occurred in nine patients (45\%). Five required treatment with a Fresnel prism or ocular occlusion to avoid intractable diplopia [double vision]. There were 15 patients in Group $B$ [injection via transconjunctival supratarsal route] and only 2 of them developed post-treatment superior rectus underaction. Injecting Botulinum toxin A to induce protective ptosis via a transconjunctival supratarsal route was significantly less likely to induce superior rectus underaction than when given via the transcutaneous route" [13].

\section{Glaucoma}

Genetics or congenital defects can also affect the muscles of the eye. This study looked at the distance from the corneoscleral limbus to the insertion site of the superior rectus of primary angle-closure glaucoma. Results showed, "The limbus-insertion distance of the superior rectus was $0.40+/-0.08 \mathrm{~mm}$ shorter in the primary angle-closure glaucoma group than in the normal control group. The shorter limbus-insertion distance may be another anatomic characteristic of primary angleclosure glaucoma eyes" [14].

Muscles can be shortened by a number of factors including trauma, stress or tension and spasticity. Developed by Sharon Weiselfish Giammatteo, $\mathrm{PhD}$, Integrative Manual Therapy has a number of manual therapy techniques for relaxation and elongation of the muscles of the eye [15-17].

CranioSacral Therapy (CST) and Osteopathic Cranial Therapy also address the bony attachments of the muscles in the orbit of the eye $[18,19]$.

\section{NLP associations}

From the field of neurolinguistic programming comes the idea that the direction of eye movement when a person is speaking in conversation indicates something about what is happening in the brain [20,21].

Remembered imagery or memories that include images that have been seen before like the color of a childhood home or the face of an elementary school teacher are associated with the eyes looking up and to the left in people who are right handed.

Constructed imagery or the ability to visualize and create visual fantasies is associated with the eyes moving up and to the right. Visual fantasies include being able to create in your mind's eye images that are not remembered because they have never been experienced by the eyes before.

The thesis of this article is that activities that strengthen or contribute to healing of the muscles of the eye that enable us to look up and to the right will also have a positive effect on the ability to remember images or in other words improve memory. Exercises that 
strengthen our ability to look up to the left will also strengthen the ability to visualize or imagine things we have never seen or in other words increase creativity and innovation.

In the same way that running strengthens the muscles of the legs and improves cardiovascular health. Looking up and to the right or looking up and to the left in healthy individuals should strengthen the extra ocular muscles needed to do those actions.

One exercise is to look up holding the upward gaze for five seconds, then relaxing the eyes for five seconds while focusing on breathing. Next look upward and to the left for five seconds. Without moving the head notice the thing that is farthest up and to the left. Then relax the eyes while thinking about a problem you have in your house. What could you create in order to fix the problem? Finally look up and to the right for five seconds. As you then relax your eyes, try to see with your mind's eye the house that you lived in when you were ten years old. What color was it? What was it made of? How many stories did it have? These upward looking steps can be repeated several times.

Besides surgery and medications there are a number of approaches from the field of complementary and alternative medicine that address the health and healing of muscle and tendons as well as the connective tissue throughout the body including the eyes. These approaches include integrative manual therapy, matrix energetics, osteopathic manual medicine, cranial therapy, acupuncture/acupressure (the gallbladder meridian is associated with the eyes and eyesight), reflexology, craniosacral therapy, massage, reiki, qigong and meditation.

\section{Conflict of interest}

\section{None}

\section{References}

1. Rashed RM, El-Alfy SH (2012) Ultrastructural organization of muscle fiber types and their distribution in the rat superior rectus extraocular muscle. Acta Histochem 114: 217-225. [Crossref]

2. Javed A, Wong V, Jane Young, Jon Durnian (2015) A novel case of superior rectus injury and its subsequent surgery. Case Rep Ophthalmol 6: 7-11. [Crossref]

3. Jakobiec FA, Grob SR (2017) Orbital Conjunctival Cyst Associated with the Superior Rectus-Levator Muscles: A Clinicopathologic Study. Ophthal Plast Reconstr Surg 33: e1-e4. [Crossref]

4. Hristodulopulos V, Medel R (2016) Intramuscular Lipoma of Superior Rectus Muscle Ophthal Plast Reconstr Surg 32: e52-55. [Crossref]
5. Fukuhar J, Kase S, Noda M, Ishijima K, Ishida S (2011) Extranodal marginal zone B-cell lymphoma involving superior rectus muscle: A clinicopathological case report. Oncol Lett 2: 489-491. [Crossref]

6. Verma R, Jaiswal A (2013) Multiple brain parenchymal neurocysticercosis with extraocular muscle cysticercosis affecting levator palpebral superioris and superior rectus complex: an unusual association. BMJ Case Rep

7. Wei Y, Kang XL, Del Monte MA (2016) Enlargement of the superior rectus and superior oblique muscles causes intorsion in Graves' eye disease. Br J Ophthalmol 100: 1280-1284. [Crossref]

8. Suh SY, Le A, Clark RA, Demer JL (2016) Rectus Pulley Displacements without Abnormal Oblique Contractility Explain Strabismus in Superior Oblique Palsy. Ophthalmology 123: 1222-1231. [Crossref]

9. Patel SH, Cunnane ME, Juliano AF, Vangel MG, Kazlas MA, et al. (2014) Imaging appearance of the lateral rectus-superior rectus band in 100 consecutive patient without strabismus. AJNR Am J Neuroradiol 35: 1830-1835. [Crossref]

10. Khan AO (2012) Double elevator weakening for unilateral congenital superior oblique palsy with ipsilateral superior rectus contracture and lax superior oblique tendon. $J$ AAPOS 16(3): 301-303. [Crossref]

11. Weiselfish-Giammatteo S, Kain JB, Giammatteo T (2005) Integrative manual therapy for the connective tissue system: myofascial release. Berkeley, Calif.: North Atlantic Books.

12. Langevin HM (2006) Connective tissue: a body-wide signaling network? Med Hypotheses 66: 1074-1077. [Crossref]

13. Sadiq SA, Dharmasena A (2014) Superior rectus underaction following botulinum toxin injection to induce protective upper eye lid ptosis--a comparative study of two techniques. Strabismus 22: 111-114. [Crossref]

14. Huang W, Gao X (2016) Limbus-insertion distance of superior rectus in primary angle closure glaucoma: an anterior segment OCT study. Can J Ophthalmol 51: 438-444.

15. Giammatteo T, Weiselfish-Giammatteo S (1997) Integrative manual therapy for the autonomic nervous system and related disorders: utilizing advanced strain and counterstrain technique. Berkeley, Calif., North Atlantic Books.

16. Wheeler L (2004) Advanced Strain Counterstrain. Massage Therapy Journal 43 Winter 4.

17. Giammatteo SW, Giammatteo T, Burnham K (2009) Muscle Rhythms, A Manual Therapy Approach to Muscle Physiology. Explore! 18: 2.

18. Magoun HI (1976) and Sutherland Cranial Teaching Foundation. Osteopathy in the cranial field.

19. Milne H (1998) The heart of listening: a visionary approach to craniosacral work Berkeley, Calif, North Atlantic Books.

20. Kirenskaya AV, Novototsky-Vlasov VY, Chistyakov AN, Zvonikov VM (2011) The relationship between hypnotizability, internal imagery, and efficiency of neurolinguistic programming. Int J Clin Exp Hypn 59: 225-241. [Crossref]

21. Sahebalzamani M (2014) Efficacy of neurolinguistic programming training on menta health in nursing and midwifery students. Iran J Nurs Midwifery Res 19: 503-507. [Crossref]

Copyright: (C2017 Burnham K. This is an open-access article distributed under the terms of the Creative Commons Attribution License, which permits unrestricted use, distribution, and reproduction in any medium, provided the original author and source are credited. 